\title{
Effect of the Extent of Release for Knee Balancing on Post-Operative Limb Coronal Alignment After Primary Total Knee Arthroplasty
}

This article was published in the following Dove Press journal: Orthopedic Research and Reviews

\author{
Mohammad M Alzahrani ${ }^{1}$ \\ Thomas J Wood ${ }^{2}$ \\ Lyndsay E Somerville ${ }^{3}$ \\ Steven J MacDonald (D) ${ }^{3}$ \\ James L Howard ${ }^{3}$ \\ Edward M Vasarhelyi (D) ${ }^{3}$ \\ Brent A Lanting ${ }^{3}$ \\ 'Department of Orthopaedic Surgery, \\ College of Medicine, Imam Abdulrahman \\ Bin Faisal University, Dammam, Saudi \\ Arabia; ${ }^{2}$ Division of Orthopaedic Surgery, \\ Department of Surgery, Hamilton Health \\ Sciences, McMaster University, Hamilton, \\ ON, Canada; ${ }^{3}$ Division of Orthopaedic \\ Surgery, Department of Surgery, London \\ Health Sciences Centre University \\ Campus, University of Western Ontario, \\ London, Ontario N6A 5A5, Canada
}

Correspondence: Mohammad M Alzahrani Department of Orthopaedic Surgery, College of Medicine, Imam Abdulrahman Bin Faisal University, 2835 King Faisal Road,

Dammam 34212, Saudi Arabia

Email mmalzahrani@iau.edu.sa
Introduction: Outcomes and longevity of total knee arthroplasty (TKA) depend mainly on restoring knee function, through precise bony resection and appropriate soft tissue balancing. The current literature lacks evidence regarding the degree of radiographic change after intraoperative knee balancing. The purpose of our study was to assess the degree of change in coronal lower extremity alignment by comparing pre-operative to post-operative full-length radiographs (FLR) after quantifying the degree of intra-operative knee balancing and correlate patient-reported outcomes to the extent of balancing required.

Patients and Methods: One hundred and fifty-four patients undergoing primary TKA for varus knee osteoarthritis were included in the study. The performed soft tissue releases and bony adjustments to obtain a balanced TKA intra-operatively were prospectively documented and were grouped into minimal, moderate and extensive release groups. Hip-knee-ankle angle (HKA), anatomical femoral-tibial angle (FTA), condylar hip angle (CH), medial proximal tibial angle (MPTA) and condylar plateau angle (CPA) were measured on fulllength radiographs both pre-operatively and post-operatively. Frequencies of the soft tissue releases and bony resections in addition to descriptive statistics of the measured angles on the radiographs were recorded. In addition, patient-reported outcome scores (PROMs) were compared between the grouped patients.

Results: Of those that were included in the study, 66 knees $(42.9 \%)$ required minimal release to adequately balance the knee, while $70(45.5 \%)$ required moderate release and 18 $(11.7 \%)$ required extensive release. No statistically significant differences were found in change of alignment between the groups for all the measured angles. In addition, no difference in PROMs was seen between the groups both pre- and post-operatively.

Conclusion: Although we found no association between post-operative coronal alignment of a TKA and the degree of soft tissue release and bony resection, this likely represents the fact that a balanced TKA is dynamic and not dependent on change of single radiographic parameters. Patient-reported outcomes were not impacted by the extent of releases.

Keywords: knee arthroplasty, soft tissue, balancing, alignment, outcomes

\section{Introduction}

Multiple treatment options are available for knee osteoarthritis (OA), including conservative management, total and partial knee arthroplasty. Total knee Arthroplasty (TKA) is considered the most commonly utilized surgical option for management of end-stage knee OA. Outcomes and longevity of this procedure depend mainly on restoring knee function, mainly through precise bony resection and adequate soft tissue balancing. ${ }^{1-3}$ While controversy exists in the literature on 
the adequate intra-operative soft tissue balance, the standard of care remains achieving symmetrical flexion and extension gaps ${ }^{2,4-7}$ and thus adequate varus/valgus balancing. In the current literature, there is a lack of evidence on the effect of soft tissue balancing on lower extremity alignment and the amount of change between the preoperative and post-operative radiographs. A study by $\mathrm{Gu}$ at al. assessed the effect of $5^{\circ}$ and $7^{\circ}$ valgus cuts on gap balancing and change in alignment from native in a computer-simulated model. They showed these commonly used cut parameters led to undesirable gap imbalances and changes in limb alignment. Although they assessed the change in alignment the cohort was of both balanced and imbalanced knees, also only the change in lower extremity mechanical axis was reported. ${ }^{8}$

The purpose of our study was to assess the degree of change in coronal lower extremity alignment from preoperative to post-operative on full-length radiographs (FLR) after intra-operative knee balancing. Our hypothesis is that more extensive soft tissue and bony adjustment will lead to a larger change in coronal limb alignment. Also, we aimed to assess the relationship between coronal alignment correction and patientreported outcome measures.

\section{Patients and Methods}

After obtaining ethics approval from the institutional research ethics board, patients undergoing primary total knee arthroplasty between September 2014 and December 2016 were prospectively included. All procedures were conducted at a single center by one of four adult reconstructive fellowship-trained orthopaedic surgeons. The inclusion criteria were patients more than 18 years old who underwent a posterior stabilized TKA (using intramedullary femur and extramedullary tibia guides) for varus osteoarthritis with a goal of neutral alignment and had a standing pre- and post-operative fulllength hip to ankle radiograph. The exclusion criteria were patients with inflammatory arthritis, valgus knee osteoarthritis, history of prior knee trauma, history of prior femoral or tibial osteotomy and history of knee infection. The required soft tissue release and bony adjustments to acquire a balanced TKA intra-operatively were recorded. The Pre-operative radiographs were used to template the bone cuts and understand the anatomy using a standing AP knee and full-length radiographs. The components were all metal base plate, modular PS total knees and all distal femurs were cut using an intramedullary guide and set at
5 or 6 degrees of valgus depending on patient factors and pre-operative templating. The proximal tibial resections were all cut to a neutral mechanical axis in the coronal plane and the amount of the tibial slope cut at was based on the patient's anatomy aiming for a mechanical alignment. The sequence of balancing was according to the steps followed at our center using sizing block spacers as well as trial components without any intra-operative device, we believed this would provide generalizability of our findings. These releases were then grouped in a stepwise manner (Table 1). These releases were applied until the surgeon gained a balanced knee, if at least one of the release techniques was utilized from a specific group then the knee was considered under that release grouSurgical steps were recorded immediately after the surgery was completed by completing a check list, with each surgical release or bone resection listed.

The full-length radiographs were obtained at year postTKA and then assessed by two observers using the following measurements: anatomical femoral-tibial angle (FTA), condylar hip angle $(\mathrm{CH})$, medial proximal tibial angle (MPTA) and condylar plateau angle (CPA) (Figures 1 and 2). ${ }^{9,10}$

The frequencies of each release group were calculated and reported using descriptive statistics. Mean, median and standard deviation outcomes were reported for the radiographic alignment pre-operatively, post-operatively and change between these. A Kruskal Wallis $H$-Test was used to compare the alignment change between the release groups using SPSS statistical package version 24 (SPSS Inc., Chicago, IL) based on the median of pre-operative and post-operative change of alignment for each of the measured angles.

In addition, pre-operative and post-operative patientreported outcomes (PROMs) were compared between the

Table I Soft Tissue Modification Groups

\begin{tabular}{|l|l|}
\hline $\begin{array}{l}\text { Minimal release } \\
\text { group }\end{array}$ & $\begin{array}{l}\text { 50\% deep medial collateral ligament release } \\
\text { up to mid-coronal tibial plane } \\
\text { Osteophytes (Tibial and Femoral) }\end{array}$ \\
\hline $\begin{array}{l}\text { Moderate } \\
\text { release group }\end{array}$ & $\begin{array}{l}\text { Complete deep medial collateral ligament } \\
\text { release }\end{array}$ \\
\hline $\begin{array}{l}\text { - Posterior Capsule release } \\
\text { Extensive } \\
\text { release group }\end{array}$ & $\begin{array}{l}\text { Lemimembranosus \& Posterior Oblique } \\
\text { - Sibial reduction osteotomy }\end{array}$ \\
\hline
\end{tabular}



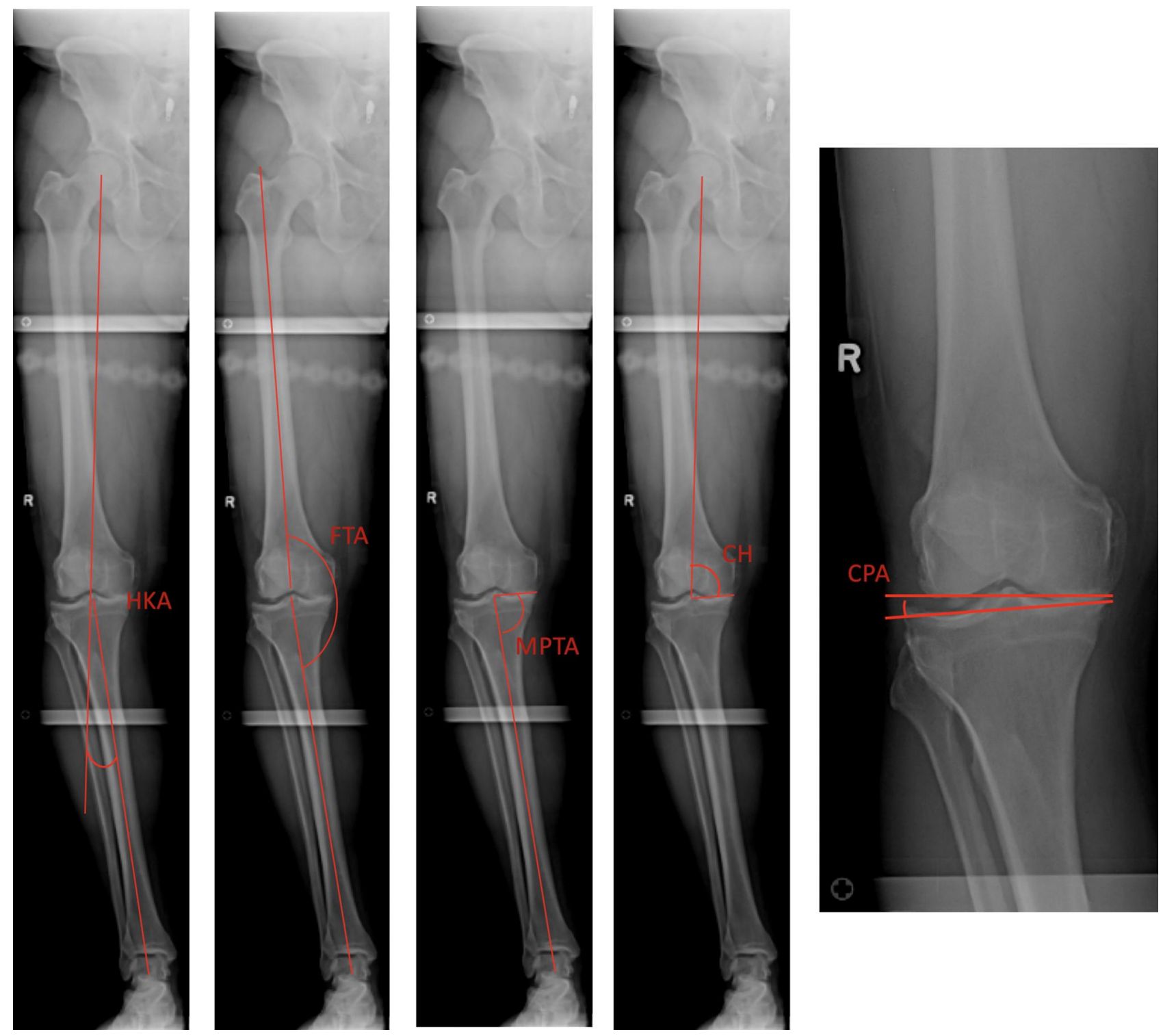

Figure I Pre-operative alignment measurements on full-length radiographs.

Notes: Copied with permission from Alzahrani, M.M., et al, Correlation of Short Knee Radiographs and Full-length Radiographs in Patients Undergoing Total Knee Arthroplasty. Journal of the American Academy of Orthopaedic Surgeons: June I, 2019 - Volume 27 - Issue II - P e5I6-e52I, DOI: I0.5435/JAAOS-D-I8-00272. ${ }^{10}$

Abbreviations: HKA, hip-knee-ankle angle; FTA, femoral-tibial axis; $\mathrm{CH}$, condylar hip angle; MPTA, medial proximal tibial angle; CPA, condylar plateau angle.

grouped patients. These included the Knee Society Score (KSS), WOMAC and SF-12 scores which were collected by the surgeons. A Kruskal Wallis $H$-Test was used to compare the KSS, while one-way ANOVA was used to compare the WOMAC and SF-12 scores between the release groups.

\section{Results}

A total of 154 patients were included in the present study. Ninety-two (59.7\%) of the patients were female and 62 were male (40.3\%) (Table 2). Average age of the patients included was 67 years old (range: 48-95), while the mean BMI was 33.8 (range: 19.1-59.7) (Table 3).
Means and standard deviations of the alignment angles were assessed pre- and post-operatively (Table 4). The mean change of alignment between the pre-operative and post-operative HKA, FTA, CH, MTPA and CPA was $5.31^{\circ}, 3.31^{\circ}, 2.4^{\circ}, 4.05^{\circ}$ and $3.64^{\circ}$, respectively (Table 4 ).

When we assessed the release grouping, we found that $66(42.9 \%)$ required minimal release to adequately balance the knee, while $70(45.5 \%)$ required moderate release and $18(11.7 \%)$ required extensive release. No statistically significant differences were found in change of alignment between the groups for all the measured angles (Table 5). 

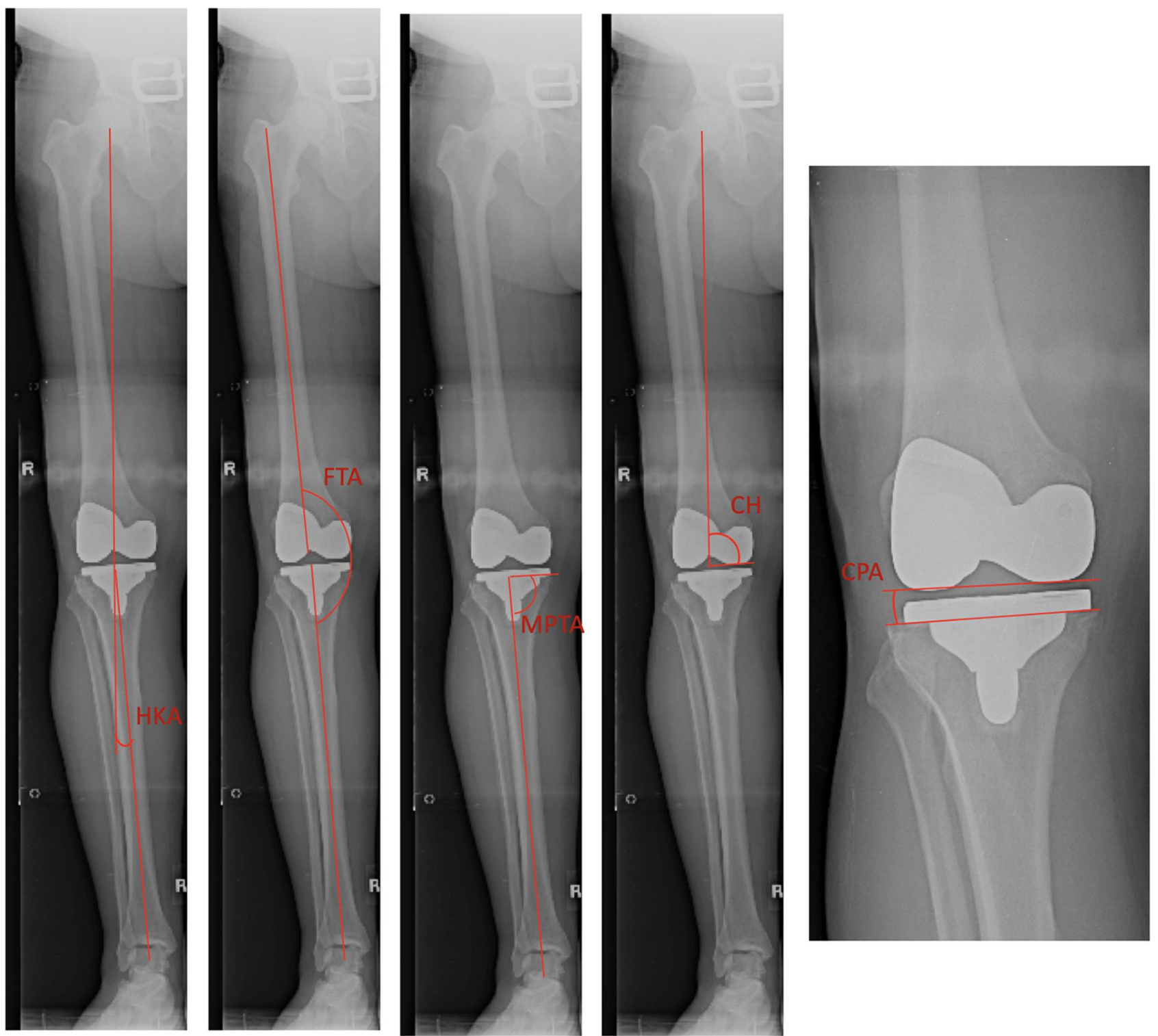

Figure 2 Post-operative alignment measurements on full-length radiographs.

Notes: Copied with permission from Alzahrani, M.M., et al, Correlation of Short Knee Radiographs and Full-length Radiographs in Patients Undergoing Total Knee Arthroplasty. Journal of the American Academy of Orthopaedic Surgeons: June I, 2019 - Volume 27 - Issue II - p e5I6-e52I, DOI: I0.5435/JAAOS-D-I8-00272. ${ }^{10}$

Abbreviations: HKA, hip-knee-ankle angle; FTA, femoral-tibial axis; $\mathrm{CH}$, condylar hip angle; MPTA, medial proximal tibial angle; CPA, condylar plateau angle.

Concerning the PROMs, no statistically significant differences were found between the patients in the three groups (minimal, moderate and extensive release) both pre- and post-operatively (Table 6,7).

\section{Discussion}

While a number of factors are involved in achieving a successful outcome when performing TKA, adequate knee balancing and alignment are considered among the most significant factors involved. ${ }^{3,11-15}$ The purpose of this study was to assess the effect of the extent of soft tissue releases and bony adjustments required to achieve a balanced TKA on the change in coronal alignment between the pre-operative and post-operative radiographs. In addition, we aimed to assess whether these had an effect on the patient-reported outcomes and knee ROM at 1 year post-operatively. We found that the extent of soft tissue release and bony adjustment had no significant impact of the change in knee coronal alignment nor patient-reported outcomes.

Obtaining a well-balanced and aligned TKA has been shown to be associated with better post-operative outcomes in the current literature. ${ }^{3,11-15}$ These goals can be adequately achieved by performing adequate bony 
Table 2 Gender Distribution Between Release Groups

\begin{tabular}{|l|l|l|l|}
\hline \multirow{2}{*}{ Grade } & \multicolumn{2}{l|}{ Gender } \\
\cline { 3 - 4 } & Female & Male \\
\hline Minimal Release Group & $\begin{array}{l}\text { Count } \\
\%\end{array}$ & $\begin{array}{l}38 \\
57.6 \%\end{array}$ & $\begin{array}{l}28 \\
42.4 \%\end{array}$ \\
\hline Moderate Release Group & $\begin{array}{l}\text { Count } \\
\%\end{array}$ & 43 & 27 \\
& $61.4 \%$ & $38.6 \%$ \\
\hline Extensive Release Group & $\begin{array}{l}\text { Count } \\
\%\end{array}$ & $\begin{array}{l}12 \\
66.7 \%\end{array}$ & $\begin{array}{l}6 \\
\text { P-value }\end{array}$ \\
\hline
\end{tabular}

Table 3 Means and p-values for Age and BMI Among Release Groups

\begin{tabular}{|l|l|l|l|}
\hline \multicolumn{2}{|l|}{ Grade } & Age & BMI \\
\hline Minimal Release Group & Mean ( \pm SD) & $70.2( \pm 8.9)$ & $34.0( \pm 7.1)$ \\
Moderate Release Group & Mean ( \pm SD) & $67.4( \pm 8.6)$ & $35.3( \pm 7.4)$ \\
Extensive Release Group & Mean ( \pm SD) & $71.8( \pm 8.9)$ & $32.0( \pm 3.5)$ \\
\hline P-value & 0.09 & 0.235 \\
\hline
\end{tabular}

Table 4 Mean Degree and Standard Deviations of Measured Angles Between Pre-Operative and Post-Operative Full-Length Radiographs

\begin{tabular}{|l|l|l|l|}
\hline Angle & $\begin{array}{l}\text { Pre- } \\
\text { Operative }\end{array}$ & $\begin{array}{l}\text { Post- } \\
\text { Operative }\end{array}$ & $\begin{array}{l}\text { Pre- to Post- } \\
\text { Operative Change }\end{array}$ \\
\hline HKA (SD) & $8.8^{\circ}\left(4.4^{\circ}\right)$ & $3.9^{\circ}\left(2.8^{\circ}\right)$ & $5.31^{\circ}\left(3.5^{\circ}\right)$ \\
FTA (SD) & $4.1^{\circ}\left(3.3^{\circ}\right)$ & $3.6^{\circ}\left(2.5^{\circ}\right)$ & $3.31^{\circ}\left(2.7^{\circ}\right)$ \\
CH (SD) & $90.3^{\circ}\left(2.4^{\circ}\right)$ & $88.6^{\circ}\left(2.3^{\circ}\right)$ & $2.40^{\circ}\left(1.9^{\circ}\right)$ \\
MPTA (SD) & $85.1^{\circ}\left(3.3^{\circ}\right)$ & $88.7^{\circ}\left(2.2^{\circ}\right)$ & $4.05^{\circ}\left(2.7^{\circ}\right)$ \\
CPA (SD) & $4.4^{\circ}\left(2.1^{\circ}\right)$ & $0.7^{\circ}\left(0.5^{\circ}\right)$ & $3.64^{\circ}\left(2.1^{\circ}\right)$ \\
\hline
\end{tabular}

Abbreviations: HKA, hip-knee-ankle angle; FTA, femoral-tibial axis; $\mathrm{CH}$, condylar hip angle; MPTA, medial proximal tibial angle; CPA, condylar plateau angle; SD, standard deviation.

resections and soft tissue releases to gain a balanced TKA. ${ }^{16-18}$ While the standard of care remains gaining symmetrical gaps in both flexion and extension, there is
Table 6 Medians and p-values of Pre-Operative and I Year PostOperative Knee Society Scores

\begin{tabular}{|l|l|l|l|}
\hline \multicolumn{2}{|l|}{ Grade } & $\begin{array}{l}\text { KS } \\
\text { Pre-Operative }\end{array}$ & $\begin{array}{l}\text { KS I Year } \\
\text { Post-Operative }\end{array}$ \\
\hline Minimal Release & Median & 95 & 183 \\
Moderate Release & Median & 89 & 190 \\
Severe Release & Median & 94 & 187 \\
\hline P value & 0.827 & 0.218 \\
\hline
\end{tabular}

Abbreviation: KS, Knee Society Score.

no consensus in the current literature on the most ideal technique to achieve this intra-operative goal. ${ }^{19,20}$ In some instances, a minimal release is all that is required to achieve a balanced TKA, while in cases of more severe knee osteoarthritis or with extensive deformity an extensive release is frequently required. In our current cohort, the sequence of soft tissue release and bony adjustments were according to the steps followed at our center.

Improvements in patient-reported outcomes and ROM after TKA have been extensively studied and reported in the literature. ${ }^{21-27}$ The vast majority of the published studies have shown improved PROMs irrespective of the extent of the soft tissue release required to achieve a balanced TKA. ${ }^{28,29}$ These improvements were also evident in our cohort, which also showed improved patient-reported outcomes post-operatively. Interestingly, there was no significant difference post-operatively between the release groups as patients who required an extensive release had as good outcomes as patient who required minimal release to achieve an adequately balanced knee. This may be attributed to the fact that the majority of the patient achieved a balanced TKA postoperatively regardless of the extent of the required release and thus a type of ceiling effect in the PROMs was observed when the patient achieved the expected good outcome.

Table 5 Medians and p-values of Pre-Operative to Post-Operative Change in Alignment

\begin{tabular}{|l|l|l|l|l|l|l|l|}
\hline \multicolumn{2}{|l|}{ Grade } & $\begin{array}{l}\text { Pre-Operative } \\
\text { HKA }\end{array}$ & $\begin{array}{l}\text { Change } \\
\text { HKA }\end{array}$ & $\begin{array}{l}\text { Change } \\
\text { FTA }\end{array}$ & $\begin{array}{l}\text { Change } \\
\text { CH }\end{array}$ & $\begin{array}{l}\text { Change } \\
\text { MPTA }\end{array}$ & $\begin{array}{l}\text { Change } \\
\text { CPA }\end{array}$ \\
\hline Minimal Release Group & Median & 8.85 & -5.55 & 0.25 & -1.30 & -3.75 & 3.15 \\
Moderate Release Group & Median & 8.0 & -4.55 & 0.35 & -1.70 & -3.50 & 3.45 \\
Extensive Release Group & Median & 10.6 & -5.40 & -2.55 & -2.35 & -3.80 & 5.45 \\
\hline P-value & 0.365 & 0.209 & 0.145 & 0.360 & 0.785 & 0.072 \\
\hline
\end{tabular}

Abbreviations: HKA, hip-knee-ankle angle; FTA, femoral-tibial axis; $\mathrm{CH}$, condylar hip angle; MPTA, medial proximal tibial angle; CPA, condylar plateau angle. 
Table 7 Means \pm SD and p-values of Pre-Operative and I Year Post-Operative WOMAC and SF-12 Scores

\begin{tabular}{|l|l|l|l|l|l|}
\hline \multicolumn{2}{|l|}{ Grade } & $\begin{array}{l}\text { SFI2 MCS } \\
\text { Pre-Operative }\end{array}$ & $\begin{array}{l}\text { SFI2 MCS I Year } \\
\text { Post-Operative }\end{array}$ & $\begin{array}{l}\text { WOMAC } \\
\text { Pre-Operative }\end{array}$ & $\begin{array}{l}\text { WOMAC I Year } \\
\text { Post-Operative }\end{array}$ \\
\hline $\begin{array}{l}\text { Minimal Release } \\
\text { Moderate Release }\end{array}$ & Mean \pm SD & $54.55 \pm 9.68$ & $54.52 \pm 9.09$ & $47.77 \pm 16.51$ & $74.49 \pm 14.67$ \\
Severe Release & Mean \pm SD & $52.90 \pm 12.35$ & $53.61 \pm 9.34$ & $45.07 \pm 15.20$ & $79.99 \pm 16.16$ \\
\hline P value & P & 0.715 & $52.85 \pm 10.77$ & $45.39 \pm 15.64$ & $77.16 \pm 18.01$ \\
\hline
\end{tabular}

Our current study has shown that although there was a change in alignment between pre-operative and postoperative measurements, there was no association between the change in coronal alignment of a TKA and the degree of release (Table 5). This likely represents the fact that a balanced TKA is dynamic and not dependent on a single radiographic measurement, as the pre-operative alignment of an arthritic knee does not give an accurate representation of the bony pathology nor the dynamic soft tissue effect. Therefore, assessment of TKA balancing is more of a live feedback from the physical examination of the knee both intra-operatively and post-operatively and not by a static radiographic assessment.

The current study has a few limitations; the inter- and intraobserver reliability of the pre- and post-operative radiographic measurements was not reported, but there is strong evidence in the literature on the reliability of these parameters. ${ }^{30,31}$ Also, the rotational profile between the pre- and post-operative measurements may have an effect on the measured values; however, this limitation was minimized by performing all radiographs by a standardized protocol at a single institution. In addition, four surgeons performed the surgical procedures which may introduce another independent variable, but the sequence of intra-operative release is similar between all the surgeons at our institute. Another limitation is the relatively small sample size but extensive releases are very uncommon clinical entity in TKA; therefore, it is difficult to include a sample that is equivalent to the larger numbers of cohorts of common clinical entities. Another limitation is that the degree and severity of arthritis was not quantified preoperatively on the included patients. It is well known that the degree of the required soft tissue release to balance the knee intra-operatively can be affected by the amount of preoperative arthritis and associated deformity.

\section{Conclusion}

The change in coronal alignment between the pre-operative and post-operative measurements in patients undergoing TKA was not associated with the degree of soft tissue releases and bony adjustments required to gain a balanced knee. We believe that this is most likely attributed to that the assessment of a balanced TKA is a dynamic one and cannot be quantified according to alignment changes on full-length knee radiographs. In addition, we have shown that although there was no difference in the PROMs between the groups both pre- and post-operatively, all the groups had improved PROMs after the replacement surgery.

\section{Ethics Statement}

This study has been approved by The Western University Research Ethics Board. Patient informed consent was obtained for all participants and is compliant with the Declaration of Helsinki.

\section{Disclosure}

Lyndsay E Somerville reports institutional support from Smith and Nephew, Depuy, Zimmer, Stryker, outside the submitted work. Steven J MacDonald reports personal fees from DePuy, A Johnson \& Johnson Company, stock or stock options from Hip Innovation Technology, JointVue, Curvafix, and Parvizi Surgical Innovation, and research support from Stryker and Smith \& Nephew, outside the submitted work. James L Howard report grants, personal fees, and institutional research support from Depuy, personal fees and institutional research support from Stryker and Smith and Nephew, personal fees from Intellijoint, and institutional research support from Zimmer, outside the submitted work. Edward Vasarhelyi reports grants, personal fees, and institutional and research support other from DePuy, and institutional and research support from Stryker, Smith and Nephew, and Zimmer Biomet, outside the submitted work. Brent A Lanting reports grants, personal fees, and institutional support from DePuy, Smith and Nephew, and Stryker, personal fees from IntelliJoint, and institutional support from Zimmer, outside the submitted work. The authors report no other potential conflicts of interest for this work. 


\section{References}

1. Fang DM, Ritter MA, Davis KE. Coronal alignment in total knee arthroplasty: just how important is it? J Arthroplasty. 2009;24(6 Suppl):39-43. doi:10.1016/j.arth.2009.04.034

2. Mihalko WM, Saleh KJ, Krackow KA, et al. Soft-tissue balancing during total knee arthroplasty in the varus knee. $J$ Am Acad Orthop Surg. 2009;17(12):766-774. doi:10.5435/00124635-200912000-00005

3. Werner FW, Ayers DC, Maletsky LP, et al. The effect of valgus/varus malalignment on load distribution in total knee replacements. J Biomech. 2005;38(2):349-355. doi:10.1016/j.jbiomech.2004.02.024

4. Jeffery RS, Morris RW, Denham RA. Coronal alignment after total knee replacement. J Bone Joint Surg Br. 1991;73(5):709-714. doi:10.1302/0301-620X.73B5.1894655

5. Insall JN, Lachiewicz PF, Burstein AH. The posterior stabilized condylar prosthesis: a modification of the total condylar design. Two to four-year clinical experience. J Bone Joint Surg Am. 1982;64(9):1317-1323. doi:10.2106/00004623-198264090-00006

6. Bellemans J, et al. The Chitranjan Ranawat award: is neutral mechanical alignment normal for all patients?: the concept of constitutional varus. Clin Orthopaedics Related Res. 2012;470(1):45-53. doi:10.1007/s11999-011-1936-5

7. Parratte S, Pagnano MW, Trousdale RT, et al. Effect of postoperative mechanical axis alignment on the fifteen-year survival of modern, cemented total knee replacements. J Bone Joint Surg Am. 2010;92 (12):2143-2149. doi:10.2106/JBJS.I.01398

8. Gu Y, Howell SM, Hull ML. Simulation of total knee arthroplasty in $5^{\circ}$ or $7^{\circ}$ valgus: a study of gap imbalances and changes in limb and knee alignments from native. J Orthop Res. 2017;35(9):2031-2039. doi:10.1002/jor.23492

9. Cooke TD, Sled EA, Scudamore RA. Frontal plane knee alignment: a call for standardized measurement. J Rheumatol. 2007;34 (9):1796-1801.

10. Alzahrani MM, Wood TJ, Somerville LE, et al. Correlation of short knee radiographs and full-length radiographs in patients undergoing total knee arthroplasty. J Am Acad Orthop Surg. 2018.

11. D'Lima DD, Hermida JC, Chen PC, et al. Polyethylene wear and variations in knee kinematics. Clin Orthop Relat Res. 2001;392 (392):124-130. doi:10.1097/00003086-200111000-00015

12. Lima DD, Chen PC, Colwell CW Jr. Polyethylene contact stresses, articular congruity, and knee alignment. Clin Orthop Relat Res. 2001;392(392):232-238. doi:10.1097/00003086-200111000-00029

13. Parratte S, Pagnano MW. Instability after total knee arthroplasty. Instr Course Lect. 2008;57(p):295-304.

14. Elmallah RK, Mistry JB, Cherian JJ, et al. Can we really "feel" a balanced total knee arthroplasty? J Arthroplasty. 2016;31(9 Suppl):102-105. doi:10.1016/j.arth.2016.03.054

15. Vince KG, Abdeen A, Sugimori T. The unstable total knee arthroplasty: causes and cures. $J$ Arthroplasty. 2006;21(4 Suppl 1):44-49. doi:10.1016/j.arth.2006.02.101

16. Babazadeh S, Dowsey MM, Stoney JD, et al. Gap balancing sacrifices joint-line maintenance to improve gap symmetry: a randomized controlled trial comparing gap balancing and measured resection. J Arthroplasty. 2014;29(5):950-954. doi:10.1016/j.arth.2013.09.036
17. Babazadeh S, Dowsey MM, Vasimalla MG, et al. Gap balancing sacrifices joint-line maintenance to improve gap symmetry: 5-year follow-up of a randomized controlled trial. J Arthroplasty. 2018;33 (1):75-78. doi:10.1016/j.arth.2017.08.021

18. Lee DH, Park J-H, Song D-I, et al. Accuracy of soft tissue balancing in TKA: comparison between navigation-assisted gap balancing and conventional measured resection. Knee Surg Sports Traumatol Arthrosc. 2010;18(3):381-387. doi:10.1007/s00167-009-0983-x

19. Matthews J, Chong A, McQueen D, et al. Flexion-extension gap in cruciate-retaining versus posterior-stabilized total knee arthroplasty: a cadaveric study. J Orthop Res. 2014;32(5):627-632. doi:10.1002/ jor.22587

20. Daines BK, Dennis DA. Gap balancing vs. measured resection technique in total knee arthroplasty. Clin Orthop Surg. 2014;6(1):1-8. doi:10.4055/cios.2014.6.1.1

21. Quam JP, Michet CJ, Wilson MG, et al. Total knee arthroplasty: a population-based study. Mayo Clin Proc. 1991;66(6):589-595. doi:10.1016/S0025-6196(12)60517-5

22. Cram P, Lu X, Kates SL, et al. Total knee arthroplasty volume, utilization, and outcomes among Medicare beneficiaries, 1991-2010. JAMA. 2012;308(12):1227-1236. doi:10.1001/2012.jama.11153

23. Pavone V, Boettner F, Fickert S, et al. Total condylar knee arthroplasty: a long-term followup. Clin Orthop Relat Res. 2001; (388):18-25. doi:10.1097/00003086-200107000-00005

24. Meding JB, Meding LK, Ritter MA, et al. Pain relief and functional improvement remain 20 years after knee arthroplasty. Clin Orthop Relat Res. 2012;470(1):144-149. doi:10.1007/s11999-011-2123-4

25. McAuley JP, Harrer MF, Ammeen D, et al. Outcome of knee arthroplasty in patients with poor preoperative range of motion. Clin Orthop Relat Res. 2002;(404):203-207. doi:10.1097/00003086200211000-00033

26. Rajgopal A, Ahuja N, Dolai B. Total knee arthroplasty in stiff and ankylosed knees. J Arthroplasty. 2005;20(5):585-590. doi:10.1016/j. arth.2005.04.002

27. Berend KR, Lombardi AV Jr., Adams JB. Total knee arthroplasty in patients with greater than 20 degrees flexion contracture. Clin Orthop Relat Res. 2006;452(p):83-87. doi:10.1097/01.blo.0000238801. 90090.59

28. Unitt L, Sambatakakis A, Johnstone D, et al. Short-term outcome in total knee replacement after soft-tissue release and balancing. $J$ Bone Joint Surg Br. 2008;90(2):159-165. doi:10.1302/0301-620X.90B2. 19327

29. Kamenaga T, Muratsu H, Kanda Y, et al. The influence of postoperative knee stability on patient satisfaction in cruciate-retaining total knee arthroplasty. J Arthroplasty. 2018;33(8):2475-2479. doi:10.1016/j.arth.2018.03.017

30. Park A, Stambough JB, Nunley RM, et al. The inadequacy of short knee radiographs in evaluating coronal alignment after total knee arthroplasty. $J$ Arthroplasty. 2016;31(4):878-882. doi:10.1016/j. arth.2015.08.015

31. Rauh MA, Boyle J, Phillips MJ, et al. Reliability of measuring long-standing lower extremity radiographs. Orthopedics. 2007;30 (4):299-303. doi:10.3928/01477447-20070401-14
Orthopedic Research and Reviews

\section{Publish your work in this journal}

Orthopedic Research and Reviews is an international, peer-reviewed, open access journal that focusing on the patho-physiology of the musculoskeletal system, trauma, surgery and other corrective interventions to restore mobility and function. Advances in new technologies, materials, techniques and pharmacological agents are particularly welcome. The manuscript management system is completely online and includes a very quick and fair peer-review system, which is all easy to use. Visit http://www.dovepress.com/testimonials.php to read real quotes from published authors. 